\title{
Professionalising the Addiction Treatment Services in Asia
}

Tay Bian How, MA, NCAC I, ICAC III, Sun Min Kim, Ph.D., CGAC, NCAC I, ICAC III, Shirley Mikell, NCAC II, Nathalie Panabokke, Ph.D.

${ }^{1}$ The Colombo Plan, Colombo, Sri Lanka; 2Adama Science and Technology University, Adama, Ethiopia; ${ }^{3} N A A D A C$, Virginia, USA

\begin{abstract}
The Colombo Plan Asian Center for Certification and Education of Addiction Professionals (ACCE) aims to professionalise the addiction treatment providers and services in the Asia-Pacific region. The initiative aims to address the growing problem of drug abuse by creating a cadre of trained staff who are equipped to utilise evidence based practices in the region. The ACCE initiative has already certified 35 Master Trainers and is in the process of training and certifying 127 national level trainers from the Colombo Plan member countries as well as 571 treatment practitioners from Afghanistan. The ACCE programmes have motivated a number of service providers and individuals with substance use disorders to be trained and credentialed. The ACCE has the status of a Certified Education Provider of the Association for Addiction Professionals (NAADAC) in the USA. The Colombo Plan's ACCE initiative is well on its way in addressing the dearth of evidence-based practitioners and trained addiction treatment professional and in the region and playing a vital role in professionalizing the addiction treatment services in the region.
\end{abstract}

\section{Background on the drug problem}

The World Drug Report 2012 documents a prevalence of 153 million to 300 million people aged between 15 - 64 years in age as having used an illicit substance at least once during their life time. ${ }^{1}$ This accounts for $3.4-6.6$ percent of the world's population. Problem drug users are reported as having a prevalence of 15.5 million -38.6 million with 99,000 - 253,000 deaths occurring globally as a result of illicit drug use. ${ }^{1}$

The approach taken to counter the evils of drug use and addiction has been one of prohibition with punitive measures taken against drug users and dealers. However, the "war on drugs" has not been very successful around the world with the wins being seen on the side of the drugs and those who deal them. The futile attempts to curb the demand for drugs have brought about a shift towards a health related treatment approach in dealing with drug use and addiction. Efforts to prevent problems associated with drug use and to bring drug addicts for treatment have increased. In 2008, the Reference Group to the United Nations on HIV reported that $20 \%$ of drug addicts received treatment for their drug dependence. ${ }^{1}$ Opioids, namely heroin, continue to be 
the dominant drug accounting for treatment demand in Asia and Europe.

Opioids are also seen to contribute to treatment demand in Africa, North America and Oceania. The need for treatment is further emphasized by the increased risk of the spread of HIV/AIDS and other blood borne diseases such as hepatitis due to the increase in injecting drug use and sexual risk behaviour practised by the addicts. The prevalence rate for injecting drug users in 2008 was noted to be 16 million with 3 million living with HIV. ${ }^{1}$ Sharing of needles is one of the main modes of transmission, and thus, the need for professional, evidence based practices in the treatment of substance abuse and addiction is necessary. The gap between the number of addicts seeking treatment, and the global prevalence of problem drug users emphasizes, the need for increased availability in treatment services. Addiction is a chronic, relapsing brain disease characterized by compulsive drug seeking and use, despite terrible consequences that accompany it. Addiction treatment involves long term care, multiple interventions, constant monitoring and the use of a variety of evidence based practices, aimed at keeping the problem drug user in recovery. The increasing number of problem drug users and futile attempts at reducing the demand meant that treatment services had to be developed, expanded and improved, in order to attempt, to reduce the drug problem at hand.

\section{Colombo Plan and the Drug Advisory Programme}

The ColomboPlan is one of the oldestregional inter-governmental organisations dating back to the 1950s. It was conceived at the Commonwealth Conference on Foreign Affairs held in Colombo, Sri Lanka in 1950, and was launched on 1, July 1951 by Australia, Canada, India, Pakistan, New Zealand, Sri Lanka and the United Kingdom. It has since expanded to include 27 member countries including non-Commonwealth countries and countries belonging to regional groupings, such as ASEAN (Association of South-East Asian Nations) and SAARC (South Asian Association for Regional Cooperation). The Colombo Plan is based on a partnership concept of self-help and mutual-help, aimed at improving the socio-economic progress of its member countries. The four main permanent programmes conducted by the Colombo Plan include the Drug Advisory Programme (DAP), Programme for Public Administration and Environment (PPA \& ENV), Programme for Private Sector Development (PPSD) and the Long-Term Scholarships Programme (LTSP).

The Colombo Plan was the first intergovernmental organisation in Asia, to address the issue of drugs in the region. The Drug Advisory Programme (DAP) was established in response to the changing needs of member countries facing multi-faceted problems due to illicit drug production, trafficking and abuse. The DAP has several landmark achievements in assisting Colombo Plan member countries in the combat against drug scourge. ${ }^{2}$ The DAP was instrumental in assisting member countries in the establishment of national drug focal points, formulation of national drug policies and strategies and in 
the reduction of demand for drugs.

Notable initiatives in the reduction of demand for drugs in the region include the implementation of the Afghan initiative, mobilisation of faithbased organizations, approaches, establishment of outreach drop in centers, integration of life skills in preventive drug education curriculum, the Asian Recovery Symposium and the Asian Youth Congress.

\section{Asian Centre for Certification and Education of Addiction Professionals}

The Asian Center for Certification and Education of Addiction Professionals (ACCE) was established on the 16 February, 2009 by the Colombo Plan Council as the training and credentialing arm of the Drug Advisory Programme. Lack of evidence-based treatment services, a dearth in trained addiction treatment staff and a lacuna of standardised curricula for addiction treatment professionals in the region were among the key reasons for its establishment. $^{3}$

Since 2009, the ACCE programme has grown from strength to strength, and positioned itself to cater to a niche market of targeted beneficiaries by transforming into a specialised technical unit. The ACCE implemented 50 initiatives in 2012, of which 33 were training workshops. A total of 1,396 individuals participated in the various ACCE programmes, and to date, 35 addiction treatment professionals have been credentialed. The ACCE team has also completed 13 training programmes for a total of 360 treatment providers, from Afghanistan, in 2012. Since 2011, a total of 398 Afghans have been trained, out of 571 that were initially identified in the national capacity building of the country. The pool of master trainers in Afghanistan was also expanded, to accelerate the process of training Afghan treatment practitioners. The ACCE Commission was also established in 2012, and consists of representatives from 10 member countries of the Colombo Plan for Cooperative for Economic and Social Development in Asia and the Pacific.

To ensure the successful implementation of its activities in a timely manner, and keeping in mind the goals and objectives of the Colombo Plan, the ACCE is equipped with a highly competent and qualified team of international professionals, with over 20 years experience in the field of drug addiction. Each team member of ACCE is not only an expert in a specific area in the discipline of addiction, but also a representative of a particular geographic area and proficient in the local language and culture.

At present, the ACCE has the status of an internationally approved NAADAC education provider in the addiction field. The ACCE programme collaborates with NAADAC for advice and products, as it is the largest in addiction field for credentialing. NAADAC represents professional interests of more than 75,000 addiction counsellors, educators and other addiction-focused health care professionals in the United States, Canada and overseas. 
NAADAC's members are addiction counsellors, educators and other addiction-focused health care professionals, who specialise in addiction prevention, treatment, recovery support and education. An important part of the healthcare continuum, NAADAC members work to create healthier individuals, families and communities through prevention, intervention, quality treatment and recovery support. ${ }^{4}$

Similarly, the goal of this initiative is to create a cadre of addiction professionals by enhancing their knowledge, skills and competence, thereby enabling them to provide quality service and care for recovering individuals. The ACCE initiative aims to build international treatment capacity through training, professionalising and expanding the regional treatment workforce. The credentialing process prepares addiction treatment staff for professional certification, at the entry level, by providing the latest information about drug addiction and treatment. It also facilitates hands-on activities to develop skills and confidence, in a new (or minimally trained) treatment workforce.

The ACCE has embarked on the certification of addiction professionals, in Afghanistan, Bangladesh, Bhutan, India, Indonesia, Malaysia, Maldives, Philippines, South Korea, Thailand and Sri Lanka. In view of its specialisation, the ACCE has funding to train beyond the borders of the 27 member countries of the Colombo Plan, which include Africa, UAE and Central Asian countries, which are not Colombo Plan member countries.

The ACCE has developed a global curricula pertaining to addiction treatment, guiding recovery of women (GROW), and recovery of addicts. The curricula are able to provide a regional standard that encourage addiction professionals to continue learning to provide quality services to their clients. A series of curricula on diverse subjects has also been developed, adapted and translated for implementation in Indonesia, Afghanistan, Pakistan, Sri Lanka, South Korea and Central Asia.

The Bureau for International Narcotics and Law Enforcement Affairs (INL) of the US Department of State prepared a series of global training programmes, appropriate for the certification of addiction professionals in the region.

A credentialing process was also developed to professionalise addiction treatment services, and provide a formal indicator about the current knowledge and competence at the national and regional level. This validates skills, knowledge and competence of individuals, carrying out their duties optimally, within an addiction treatment setting. 


\begin{tabular}{|l|l|}
\hline The Basic Training Series Comprises of Eight Separate Curricula \\
\hline Curriculum 1 & Physiology and Pharmacology for Addiction Professionals \\
\hline Curriculum 3 & $\begin{array}{l}\text { Mental and medical disorders that often co-occur with substance } \\
\text { use disorders }\end{array}$ \\
\hline Curriculum $\mathbf{4}$ & Basic counseling skills for addiction professionals \\
\hline Curriculum 5 & $\begin{array}{l}\text { Screening, assessment and treatment planning for addiction } \\
\text { professionals }\end{array}$ \\
\hline Curriculum 6 & Case management for addiction professionals \\
\hline Curriculum 7 & Ethics for addiction professionals \\
\hline Curriculum 8 & Crisis intervention for addiction professionals \\
\hline
\end{tabular}

\begin{tabular}{|l|l|}
\hline \multicolumn{2}{|l|}{ ACCE Additional Curricula } \\
\hline Curriculum A & Psycho education for clients and family members \\
\hline Curriculum B & Enhancing life skills in drug treatment and rehabilitation \\
\hline
\end{tabular}

The programme offers three levels of credentials, namely the Basic Level (ICAC I), Clinical Level (ICAC II) and Advanced Level (ICAC III). The Basic Level of Credentialing requires the applicant, to have at least one year of full time, i.e., 1,500 hours of experience in supervision, in drug and alcohol addiction. The clinical Level requires two years or 3,000 hours of experience in supervision, and the Advanced Level requires at least five years of work experience or 8,000 hours of experience in supervision. ${ }^{5}$ Written verifications of competencies include counselling skills and functions, as observed by supervisors or other health care professionals, as well as documentation of the applicant's contact hours of education and training in alcoholism, and drug abuse or related counselling subjects. The ACCE credentialing programme is the first of its kind in the Asia, to professionalise addiction treatment services in the process of implementing evidence-based practices.

\section{Benefits of certification}

The need for certification resulted in the professionalisation of the field of addiction and substance use disorders. There were certain requirements that the counsellors had to fulfill to be eligible for certification. This meant that much like the evidence based practices followed by addiction counsellors in treatment and prevention services, there were also validated methods by which addiction professionals were recognised. Validation of their skills, knowledge and competency was conducted through application and testing, combined with training and education, providing the basis for the credentialing process. Certification provided a declaration of the individual's competencies and 
enhanced their employability and career advancement, and thus, counsellors were able to put into practice, their skills and knowledge which enhance their commitment and motivation to the job. The certification system for addiction professionals involved a structured, systematic process, through which people intending or performing clinical practices, acquired the skills necessary, to optimally perform their duties, within an addiction treatment setting.

Certification provided an opportunity for addiction professionals, to demonstrate that the services were being run effectively. The certification system, set by a group of experts in the field of addiction, produced a set of criteria for the levels of credentials, which consisted of standards that had to be met by those who apply for certification. The application process involved the evaluation of competence, skills and testing instruments, to validate baseline knowledge from each level of credentials.

The process of achieving and maintaining the certification also helps to ensure, that the services were being constantly monitored, evaluated and improved. Credentialing allowed for the quality of addiction prevention, intervention, treatment and aftercare services to be standardised. It also allowed for the monitoring of the abilities of those who worked in the addiction field, by setting a benchmark for professionals. This is vital to ensure that treatment services are effective, and are aimed at maintaining recovery levels and prevent drug use.

ACCE examinations for credentialing 30 candidates of the first batch which included members of the National Certification Board of Indonesia, National Trainers of Indonesia and two ACCE Commissioners were conducted in Jakarta last year.

The Colombo Plan programme undergoes constant monitoring and evaluation, in order to determine how well the training programme is meeting its objectives, and to successfully implement it to meet its objectives. The ACCE Team gathers information during their training programmes, to monitor and evaluate their training materials, methodology and practices.

The results obtained from the analysis of this information allow the ACCE Team to tailor their training, to meet the needs of the various countries and improve their own training skills and techniques if necessary.

A sample of 67 participants was taken from those trained in the ACCE Regional Training of Trainers (TOT) programme, for monitoring and evaluation purposes. Fifty-six percent $(56 \%)$ of the sample had a university education, while $34 \%$ of them had a post-graduate qualification. The information obtained from the trainings conducted in Afghanistan was analysed separately, as there were significant differences between educational backgrounds of the Afghan participants, when compared to participants from other parts of the 
region. The analysis uses a sample size of 130 participants, to monitor and evaluate the success of the training programme in Afghanistan. Both analyses illustrated that the ACCE training programmes, either in Afghanistan or other countries were well received.

Participants are also asked to complete training feedback forms to ensure the effectiveness of the training programme. Evaluations of training from ACCE 2012 Regional training and from the Afghan training are as follows:

Table 1: Evaluation of ACCE training in 2012

\begin{tabular}{|c|c|c|c|c|c|c|c|}
\hline \multirow{2}{*}{\multicolumn{2}{|c|}{ Components }} & \multicolumn{3}{|c|}{ Regional Training } & \multicolumn{3}{|l|}{ Afghanistan } \\
\hline & & \multirow{2}{*}{\begin{tabular}{|l|}
$\begin{array}{l}\text { Excellent/ } \\
\text { Good }\end{array}$ \\
$99 \%$
\end{tabular}} & \multirow{2}{*}{$\begin{array}{c}\text { Average } \\
1 \%\end{array}$} & \multirow{2}{*}{$\begin{array}{r}\text { Poor } \\
0 \%\end{array}$} & \multirow{2}{*}{$\begin{array}{c}\begin{array}{c}\text { Excellent/ } \\
\text { Good }\end{array} \\
93 \%\end{array}$} & \multirow{2}{*}{$\begin{array}{c}\text { Average } \\
7 \%\end{array}$} & \multirow{2}{*}{$\begin{array}{r}\text { Poor } \\
0 \%\end{array}$} \\
\hline A & $\begin{array}{l}\text { Achievement } \\
\text { of training } \\
\text { objectives }\end{array}$ & & & & & & \\
\hline B & $\begin{array}{l}\text { Knowledge and } \\
\text { skills gained, } \\
\text { relevant to my } \\
\text { current work }\end{array}$ & $97 \%$ & $3 \%$ & $0 \%$ & $95 \%$ & $5 \%$ & $0 \%$ \\
\hline $\mathrm{C}$ & $\begin{array}{l}\text { Training } \\
\text { schedule and } \\
\text { duration }\end{array}$ & $96 \%$ & $4 \%$ & $0 \%$ & $89 \%$ & $8 \%$ & $3 \%$ \\
\hline D & $\begin{array}{l}\text { Training } \\
\text { methodology }\end{array}$ & $100 \%$ & $0 \%$ & $0 \%$ & $83 \%$ & $8 \%$ & $9 \%$ \\
\hline E & $\begin{array}{l}\text { Training } \\
\text { materials and } \\
\text { handouts }\end{array}$ & $96 \%$ & $3 \%$ & $0 \%$ & $88 \%$ & $8 \%$ & $4 \%$ \\
\hline F & $\begin{array}{l}\text { Training venue } \\
\text { and food }\end{array}$ & $90 \%$ & $10 \%$ & $0 \%$ & $94 \%$ & $3 \%$ & $3 \%$ \\
\hline G & $\begin{array}{l}\text { Accommodation } \\
\text { (if any) }\end{array}$ & $98 \%$ & $2 \%$ & $0 \%$ & $93 \%$ & $7 \%$ & $0 \%$ \\
\hline
\end{tabular}

To substantiate the usefulness of the ACCE training, the ACCE team conducted individual interviews and a Focus Group Discussion in Cebu, Philippines from $15^{\text {th }}$ to $25^{\text {th }}$ January 2013. Participants are asked for their opinion of the training, as part of a qualitative exploration of the monitoring and evaluation of the ACCE programmes. Qualitative research allows us to explore the impact and meaning of certification for substance use disorder counselling.

Interviews were conducted using a semi-structured interview format. 29 participants, five females and 25 males took part in the study. Five participants were non-recovering persons and 25 were recovering persons. The participants 
consisted of nurses, addiction counsellors, two psychologists, social workers, case managers and voluntary counsellors. The participants were interviewed and asked three open ended questions on the certification process.

What is/are your motivation(s) to take the certification course?

What is/are your expectation(s) of the certification course?

What does "being credentialed" mean to you?

Each interview lasted 30 minutes and was conducted over the two week training period. A Focus Group Discussion was also conducted with four participants.

\section{Motivation and expectations for taking the certification course}

Research showed that motivation for taking the certification was very high. Participants were keen about addiction training. It was also noted that the participants who were recovering drug addicts, viewed training and education, as not only a means to improve job performance, but also for personal growth.

Some of the comments made by the participants are below:

"The training makes me mature and helps me to find out what's lacking in my own recovery."

"I am always 'hungry' for knowledge in the field I do not want to rely on my own recovery experience. People are different, so, I need to learn about how to help others."

"I have anxiety, because, I feel inadequate. I would watch YouTube for counselling skill training. I am always looking for training."

Those with professional degrees and training considered the certification course as an opportunity to enhance their job performance. One of the participants said "What I get from here, I will give to them (my clients)".

\section{Defining the role of SUD Counsellors}

Participants felt that there was a lack of systematic educational courses in substance use treatment. They had the opportunity to attend workshops and conference which provided further education and knowledge, but strongly felt that, the information obtained was fragmented.

"By systematic learning, I know what I need to know and based on the knowledge, I know now, what I should do and should not do in the field."

"My practice is based on my recovering experience and books. I need more structure in training. I got bits of training here and there but that was not enough." 
Participants were keen on expanding their knowledge base and broadening their perspectives. They wished to pay attention to the core functions, identified by experts in substance use treatment field.

"Most of my knowledge is gained through 'in house' training which can be 'pass-down'. I find what has happened to me, I also do the same for my client, same way, same thing."

\section{Opportunity to evaluate performance:}

In Asia, many of the substance use disorder counsellors are often recovering substance users. The recovering participants confess that they lack the education and knowledge on substance use disorders, and wish to expand their knowledge. The certification process also redefines the role of substance use disorder counsellors which appears to give the recovering counsellors, the confidence to work in the field.

"I am always doubting myself. I lack self-confidence. I did what my previous counsellor did to me, and found myself doing the same thing to my counsellor"

"It gives me chance to find out what is lacking for my own recovery."

"By taking the test, it will help me to see where I stand."

"Help me to communicate with other professionals with confidence."

\section{Equipped counsellor}

The counsellors undergo a training to ensure that they are equipped with the knowledge, skills and experiences necessary to perform effectively in their role. This gives the counsellors, the confidence to work in what is known to be a very challenging environment.

"I know how to save myself, but that does not mean I know how to save others. It gives me a chance to become a professional."

\section{Sign of success: Open door}

The certification course provides a sign of success or a symbol of achievement for recovering persons, who have been considered as failures, many times in their lives, while being addicts. It gives them a chance to give something back to the community by doing something that is very important to them and close to their heart.

"It would be a great success in my life, if I get a certificate. I will hang on the wall and remind myself, that I can do it."

"It would allow me to do, what I love and it would be a sign of success" 


\section{Validation, Affirmation and Recognition}

In addition to standardising and professionalising the addiction treatment field, the certification process provides an opportunity for participants to see their services objectively. The process allows participants see their practice objectively. In the case of recovering substance users working in the field, the certificate obtained validate their experiential knowledge which, the addiction treatment field has not yet recognized. It provides them with public recognition of their experience and skills in the field, amongst addiction professionals and experts. The recognition that substance use disorder counselling is a unique profession, where an individual's experiential knowledge can be refined through proper education and skills training, is a big step in the development of the treatment field.

"It gives me additional structure that I feel, I belong to."

"If I get certified through a prestigious organisation like CP, it would protect me and give me credibility."

The advantages of introducing a certification process for substance use disorder counsellors are quite clear. In addition to standardizing and professionalising the treatment field, credentialing provides counsellors with much needed knowledge, skills and confidence to work in what is known to be a very taxing, but rewarding field. The Colombo Plan ACCE programme is the first to introduce such an initiative for the Asian region. As the programme grows from strength to strength and becomes accepted globally, the training initiatives are also introduced to other countries in Africa, Central Asia and the Middle East. The ACCE programme continues to make a meaningful contribution to the global combat against drugs.

\section{References}

1. United Nations Office of Drugs and Crime. (2012) World Drug Report 2012 (www.unodc.org/unodc/en/data-and-analysis/WDR-2012.htm) Accessed on 18, February 2013

2. The Colombo Plan. (2003) The Drug Advisory Programme's $30^{\text {th }}$ Anniversary Book

3. United Nations Office of Drugs and Crime (2013) $56^{\text {th }}$ Session of Commission on Narcotics Drugs 
4. World situation with regard to drug trafficking and recommendations of the subsidiary bodies of the Commission: Reports by intergovernmental organizations on drug control activities (www.unodc.org/unode/en/ commissions/CND/session/56.html) Accessed on 12 March, 2013

5. NAADAC, The Association for Addiction Professionals

6. Available from: http://www.naadac.org/about Accessed on 15 March, 2013

7. The Colombo Plan, ACCE (2012) Minutes of First ACCE Commission Meeting 